\title{
Cuidados com a infância e a adolescência por meio de brinquedoteca comunitária
}

\author{
Caring for children and teenagers \\ with the aid of a toy library
}

\author{
Andrea Perosa Saigh JURDI' \\ Maria Lucia Toledo Moraes AMIRALIAN²
}

\begin{abstract}
Resumo
Este artigo tem por objetivo relatar uma intervenção baseada no referencial da teoria winnicottiana, em uma brinquedoteca comunitária que atende crianças e adolescentes em situação de vulnerabilidade social. Seguiu-se a metodologia da pesquisa-ação, cuja estratégia consistiu em supervisão de estagiários e brinquedistas, coleta de dados por documentos, relatos e narrativas de moradores, pesquisa bibliográfica e intervenção na brinquedoteca. Como resultado avaliou-se que as relações que se estabeleceram, baseadas na confiabilidade, fidedignidade e constância das ações, proveram as crianças e adolescentes de um ambiente humano que permitiu o brincar espontâneo e criativo, tornando-os menos vulneráveis frente aos desafios encontrados. A intervenção baseada nos pressupostos da teoria winnicottiana possibilitou ampliar o trabalho para além das relações individuais e fortalecer as práticas coletivas, criando estratégias de composição entre o campo da saúde e do social.
\end{abstract}

Unitermos: Adolescência. Infância. Jogos e brinquedos. Suscetibilidade a doenças.

\begin{abstract}
The aim of this article is to report an intervention, based on the framework of Winnicott's theory, in a community toy library that serves children and teenagers in situations of social vulnerability. The methodology followed was action research: the strategy was the supervision of interns and toy librarians, collection of documentary data and narrative reports by residents, bibliographic research and intervention in the playroom. As a result, it was found that the relationships that were established, based on trustworthiness, reliability and consistency of actions, provided children and teenagers with a human environment that allowed spontaneous and creative play, making them less vulnerable to the challenges encountered. The intervention based on the assumptions of Winnicott's theory made it possible to expand the work beyond the individual relationships and strengthen collective practices, creating strategies of composition between the health and the social fields.
\end{abstract}

Uniterms: Adolescents. Childhood. Play and playthings. Diseases susceptibility.

Este artigo tem por objetivo relatar uma intervenção com crianças e adolescentes em situação de vulnerabilidade social, em uma brinquedoteca comunitária de um bairro da periferia da zona oeste do

४

1 Universidade Federal de São Paulo, Curso de Terapia Ocupacional. Campus Baixada Santista, Av. Ana Costa, 95, Vila Mathias, 11060-001, Santos, SP, Brasil. Correspondência para/Correspondence to: A.P.S. JURDI. E-mail: <andreajurdi@gmail.com>.

2 Universidade Federal de São Paulo, Instituto de Psicologia. São Paulo, SP, Brasil.

Artigo elaborado a partir da tese de A.P.S. JURDI, intitulada"A ética do cuidado e do encontro: a possibilidade de construir novas formas de existência a partir de uma brinquedoteca comunitária". Universidade Federal de São Paulo, 2010. 
município de São Paulo, no ano de 2007. Em parceria com uma associação de moradores, o Centro de Convivência Previdência4 (Cecco Previdência) propõe que a atenção a crianças e adolescentes em situação de risco social pode ser feita por meio de uma intervenção que resgate a possibilidade do brincar, da atividade criativa e do gesto espontâneo, como forma de reduzir a situação de vulnerabilidade.

A intervenção a ser relatada inicia seu percurso a partir do trabalho proposto pelo Cecco Previdência, porém o amplia e assume contornos mais nítidos a partir das práticas cotidianas da brinquedoteca comunitária e no contato com o território onde ela está instalada. Na composição deste estudo, a teoria winnicottiana permitiu abordar a complexidade de indivíduos em seu território, com questões sociais urgentes, pois encontra, na relação entre psiquismo e cultura, um novo pensamento que permite a passagem de criação e de existência lúdica, criadora de indivíduos e de mundos. Nesse sentido, a teoria de Winnicott discute o homem no mundo como uma unidade e sempre fala do homem juntamente à soma de suas experiências culturais (Winnicott, 1959/1975).

Trata-se de crianças e adolescentes, moradores de um bairro da periferia da cidade de São Paulo, que sofrem com a falta de recursos para a sobrevivência, que travam lutas cotidianas para ter seus direitos garantidos e não ficarem submetidos à violência, às drogas, às situações de humilhação e exclusão social. O ambiente social e familiar que deveria cuidar e acolher provoca, muitas vezes, situações de negligência e abandono. A falta de cuidado e sustentação psíquica coloca-os em situação de vulnerabilidade e provoca um comportamento de reação ao ambiente, em vez de criação e transformação.

As crianças e adolescentes que chegam à brinquedoteca criada por esse serviço buscam espaço para brincar, pois na desorganizada ocupação do território não sobraram espaços disponíveis para praças, parques ou campos de futebol. Restaram-Ihes as moradias com espaços exíguos, os becos, as vielas e a rua, espaço públi-

$\boldsymbol{\nabla} \mathbf{\nabla} \boldsymbol{\nabla}$ co que também traz muitas ameaças. Diante de um mundo que foge ao controle e se apresenta como algo que ainda não pode ser percebido como próprio e os atinge como perigo, gerando descrença, ser menos vulnerável é apropriar-se das coisas da vida, é dar sentido ao que é vivido. Em um ambiente sustentado nas relações de confiança, a brinquedoteca propiciou às crianças a experiência de um modo de existir baseado na crença no outro e, dessa forma, um modo de se relacionar com base em sua criatividade ante dos desafios propostos pelo ambiente.

No campo da psicanálise, Winnicott acabou dando à clínica psicanalítica com crianças uma nova maneira de pensar a saúde e a infância, de tal forma que integrou ao determinismo presente nos textos freudianos a ideia de que a criatividade e a espontaneidade também fazem parte dos processos de constituição do si mesmo. Além disso, alerta para o fato de que as bases da saúde mental do adulto se encontram em sua infância e adolescência. O conceito de saúde desenvolvido na teoria winnicottiana leva a pensar indivíduo e sociedade de outro modo, e a perceber como um ambiente social hostil pode provocar efeitos devastadores no processo de amadurecimento pessoal de cada uma dessas crianças. Partindo-se do princípio de que a saúde da sociedade depende da saúde mental dos indivíduos que a compõem e de que esta última é necessária para que todos possam exercer seu papel social, tem-se que uma sociedade democrática encontra-se ameaçada, em termos de saúde, quando seus membros permanecem em risco social, por não terem seus direitos garantidos ou por estarem desprovidos de um ambiente suficientemente bom para possibilitar sua integração pessoal e seu amadurecimento.

Para Winnicott (1967/1999a), não se pode avaliar um homem ou uma mulher sem levar em conta seu lugar na sociedade, uma vez que esta existe como estrutura ocasionada, mantida e reconstruída por indivíduos. O autor ressalta que não pode haver realização pessoal sem a sociedade, independentemente dos processos coletivos que a compõem. O amadurecimento pessoal

- Os Centros de Convivência e Cooperativa são serviços que compõem a rede de saúde da Secretaria Municipal de Saúde (SMS) da Prefeitura do Município de São Paulo. Foram criados em 1989, quando a SMS, comprometida com as diretrizes da reforma sanitária e psiquiátrica, reformulou toda a rede de atenção à saúde, instaurando serviços territoriais de saúde mental substitutivos ao modelo hegemônico centrado nas internações psiquiátricas e outras práticas manicomiais (Galletti, 2007). 
depende fundamentalmente de dois fatores: da tendência inata à integração e à sobrevivência, e de um ambiente que torne possível tal realização. Ao definir a teoria do amadurecimento pessoal ou a teoria do desenvolvimento emocional do ser humano, é preciso esclarecer que ela inclui a história total do relacionamento individual da criança até seu meio ambiente específico. Essa história não se refere apenas à compreensão do crescimento emocional do bebê, mas também leva à compreensão do crescimento emocional da pessoa que cuida desse bebê, ou seja, do ambiente responsável pelas condições facilitadoras para que seu crescimento se efetive.

O ambiente, seja ele descrito como ambiente físico ou humano, é concebido por Winnicott como facilitador (ou não) para que de fato ocorram as várias tendências individuais herdadas. No início absoluto e depois relativamente importante, ele possibilita a constituição do ser humano, mas também pode enfraquecer e até interromper o desenvolvimento individual (Winnicott,1990).

Araujo (2007) ressalta que o conceito de ambiente definido por Winnicott tem duas características essenciais. A primeira diz respeito à adaptabilidade, ou seja, ao ambiente dinâmico que se adapta, desadapta e readapta às necessidades mutáveis do indivíduo. A outra característica é sua qualidade humana, sendo o ambiente proposto por Winnicott não apenas o meio ambiente físico, mas, fundamentalmente, o ambiente que adquire características humanas e auxilia o indivíduo em sua jornada rumo à independência. Nesse processo de vir a ser, o indivíduo necessita de um ambiente que the forneça condições de estabelecer laços sociais, de manter sua individualidade e sua singularidade nas ações coletivas, que lhe permita criá-lo e recriá-lo a todo momento.

No processo de amadurecimento descrito por Winnicott (1963/1983a), o indivíduo que caminha da dependência para a independência realiza uma jornada que permite estudar e discutir ao mesmo tempo fatores pessoais e ambientais. "Nesta linguagem normalidade significa tanto saúde do indivíduo como da sociedade, e a maturidade completa do indivíduo não é possível no ambiente social imaturo ou doente" (Winnicott, 1963/1983a, p.80).
Assim, prover a criança na saúde é prover o ambiente facilitador da saúde mental individual e do desenvolvimento emocional, partindo do princípio de que saúde é maturidade de acordo com a idade cronológica do indivíduo. Se saúde é maturidade, a imaturidade é concebida como a saúde mental deficiente, sendo portanto uma ameaça ao indivíduo e uma perda para a sociedade.

O cuidado com um indivíduo depende do que Winnicott (1961/1999b) chama de "segurar", e não se refere apenas ao segurar físico (por si só, muito importante): refere-se, também, a uma interpretação mais ampla da palavra "segurar", incluindo todo o manejo físico e as condições afetivas emocionais oferecidas ao bebê pela mãe, de acordo com suas necessidades. Com o crescimento do bebê, este "segurar"estende-se à família e à sociedade que "segura" a família. Portanto, aqueles que pretendem socializar a criança estão praticando o "segurar".

Porém, ao falar da provisão ambiental, Winnicott ressalta as dificuldades que acontecem no encontro entre indivíduo e ambiente, dificuldades essas provocadoras de falhas e rupturas que podem ser traumáticas e até interromper o processo de amadurecimento. Crianças que vivem experiências de um ambiente invasivo, no qual suas necessidades não são atendidas e não são auxiliadas no processo de amadurecimento, tendem a "desacreditar" no outro e o excluem.

Em muitas das crianças que frequentavam a brinquedoteca, percebia-se que a saúde psíquica estava ameaçada por elas vivenciarem situações de responsabilidade superior a sua capacidade emocional, provocadas, muitas vezes, pelo contexto de violência e miséria em que viviam. Os sinais de imaturidade eram percebidos na relação estabelecida com seu grupo e com seus pares, marcada pelo emprego de agressões contínuas ao outro, ao espaço e aos brinquedos. Esses sinais de instabilidade e imaturidade apareciam na impossibilidade de algumas crianças atingirem estado tranquilo para que o brincar pudesse acontecer; surgiam, também, na depressão visível nas brincadeiras, na raiva de alguns e na angústia de outros. Em alguns momentos, o comportamento de algumas crianças parecia resposta-padrão ao esperado.

As falhas ambientais nos diversos estágios do desenvolvimento provocam, muitas vezes, efeitos devas- 
tadores. O ambiente pode falhar; afinal é um ambiente suficientemente bom e humano. Porém, pensa-se em padrão de falhas, padrão de invasões que podem provocar a interrupção do processo de amadurecimento. Quando o ambiente falha repetidas vezes, obriga o indivíduo a se defender desse padrão invasor, o que pode ocasionar sofrimento, rupturas, descontinuidades e o desenvolvimento de um falso sel/ ${ }^{5}$ que protegeria o indivíduo.

Winnicott (1963/1983b) destaca que, dentre as falhas do ambiente possivelmente provocadoras de descontinuidade do processo, existe a falha que foi percebida pela criança como tal, na época em que ocorreu, ou seja, houve uma provisão ambiental suficientemente boa que cessou em algum momento. Assim, a continuidade da existência, que fazia parte do que era tido como ambiente suficientemente bom, foi substituída pela reação à falha ambiental, e essa reação interrompeu o sentimento de continuidade da existência. O autor dá o nome a esse estado de coisas de deprivação e relata que esse é o ponto de origem da tendência antissocial. A tendência antissocial pode ser considerada um distúrbio de falha ambiental. O abandono constitui a base da tendência antissocial, e o menino ou menina faz entender essa falha e força a aceitar um desafio, seja pelo roubo, seja pela destrutividade (Winnicott, 1961/1999b).

Lacôrte (2008), ao considerar a tendência antissocial, explica que o indivíduo carrega dois fardos: o processo maturacional perturbado pela reação à falha ambiental e a esperança de reconhecimento da falha. Desse ponto de vista, a tendência antissocial caracteriza-se por um elemento que compele o ambiente a tornar-se importante, isto é, a criança, em razão de impulsos inconscientes, obriga alguém a tomar o encargo de cuidar dela. Isso implica que a criança acredita que há um sinal de esperança. A falta de esperança é a característica central da criança de-privada, e é nos momentos de esperança que a criança manifesta sua tendência antissocial.

Na teoria winnicottiana, é preciso envolver-se com a necessidade do paciente que obriga alguém a encarregar-se de cuidar dele. É preciso ir ao encontro do momento de esperança e corresponder-Ihe. Além do colo da mãe, há uma série de cuidados que podem ser ativados na família, na escola, no bairro, na sociedade com suas leis: o fornecimento de um ambiente que cuida e sua estabilidade podem oferecer uma nova chance para a criança, pois ela percebe ter sido uma falha ambiental o que originalmente provocou a tendência antissocial. É o ambiente que deve fornecer a nova chance para a relacionabilidade do ego,"é a estabilidade do novo ambiente que realiza a terapia" (Winnicott, 1956/ 2000, p.416).

Assim, nesta pesquisa, a construção de um espaço de brincadeira e saúde permitiu perceber que as falhas da provisão ambiental iam provocando comportamentos, reações e relações que chamavam atenção. Nesse sentido, este artigo trata de experiências emblemáticas, por trazer à tona situações que envolvem a vida dessas crianças e mostram o desencontro entre elas e o ambiente.

Compreende-se que o ambiente responsável é o que cuida do indivíduo. A brinquedoteca propôs-se a realizar esse papel de acolher e sustentar o encontro humano, com relações estabelecidas com base na confiabilidade, na fidedignidade e na constância de ações. Pôde, desse modo, prover as crianças de um ambiente que possibilitou o brincar espontâneo e criativo.

\section{Método}

A busca teórica que acompanhou os momentos deste trabalho mostrou que a brinquedoteca e a intervenção realizada apresentavam-se como fortalecedoras de uma rede de cuidados e sustentação. O trabalho cotidiano e de intervenção permitiu seguir os preceitos da pesquisa-ação: um tipo de pesquisa com base empírica, concebida e realizada em associação com a ação ou a resolução de um problema coletivo (Thiollent, 2003).

O campo para a pesquisa foi a brinquedoteca comunitária, tendo como indivíduos envolvidos as crianças e adolescentes entre quatro e quinze anos de idade, moradores do bairro, que frequentaram a brinque-

\section{2}

$\boldsymbol{\nabla} \mathbf{\nabla} \boldsymbol{\nabla}$

5 Falso selfé uma defesa do indivíduo que oculta e protege o verdadeiro self das falhas do ambiente. O falso self surge no contato com o ambiente incapaz de reconhecer as necessidades do indivíduo, obrigando-o a se submeter ou adaptar-se ao ambiente (Winnicott, 1960/1983c). 
doteca entre fevereiro e dezembro de 2007. Além das crianças, a pesquisa contou com dois brinquedistas e duas estagiárias que trabalhavam na brinquedoteca ${ }^{6}$.

A estratégia da pesquisa seguiu a seguinte ordem: conhecimento do território; supervisão de estagiárias e brinquedistas; coleta de dados por documentos, relatos e narrativas; pesquisa bibliográfica; intervenção em quatro grupos de crianças e adolescentes em dois dias da semana; e articulação da rede social de proteção à criança e adolescente na comunidade.

A pesquisa e as narrativas dos moradores do bairro foram autorizadas pela Associação dos Moradores, de acordo com o Termo de Consentimento Livre e Esclarecido, conforme a Resolução 196/96 do Conselho Nacional de Saúde.

\section{Resultados e Discussão}

Brinquedotecas são espaços configurados para que o brincar aconteça, e existem com a finalidade de atender às necessidades lúdicas e afetivas das crianças. Como as crianças e suas necessidades são diferentes entre si, as brinquedotecas têm que ter flexibilidade e ser diferentes também. Autores como Cunha (2007) e Fortuna (2008) afirmam a necessidade de espaços que privilegiem o direito de a criança brincar: seja qual for sua condição, à criança deve ser garantido o direito a um brincar criativo, que the possibilite modificar ao mundo e a si mesma.

A brinquedoteca comunitária localiza-se em uma casa da associação de moradores. O número de crianças que frequentavam a brinquedoteca era grande e evidenciava a escassez de serviços e de alternativas de lazer. Em média, na brinquedoteca, circulavam cerca de duzentas crianças toda semana. Observou-se que as crianças que a frequentavam vinham em busca de lugar para brincar, e que moravam nas ruas próximas e nas favelas do bairro - ou seja, eram geralmente moradoras da comunidade. Diferentemente do que ocorria nos demais serviços oferecidos na região (como escolas e serviços de saúde), a maioria das crianças chegava à brinquedoteca por vontade própria e desacompanhada, sendo poucas as trazidas por familiares.

Muitas dessas crianças viviam com a família, frequentavam a escola e pareciam não apresentar problemas em seu processo de amadurecimento. Outras tantas chegavam com problemáticas intensas, expostas a situações de violência, com problemas de inserção escolar e comprometimento no aprendizado. Essas crianças exigiam um cuidado maior e mais intenso, pois apresentavam um grau de imaturidade que comprometeria sua saúde mental. Viviam em condições precárias, tendo experiências cotidianas de situações de extrema exclusão social, e estavam em situação de risco.

Entende-se neste artigo que a situação de risco acaba se traduzindo por dificuldades na frequência e no aproveitamento escolar, assim como nas condições de saúde e nas relações afetivas consigo mesmo, com a família e com o mundo. Observou-se claramente que essas crianças em situação de sociabilidade eram marcadas pela agressividade e destrutividade, e que a falta de diálogo entre elas era motivo de constantes agressões físicas.

Foram encontradas na brinquedoteca crianças que lutavam pela própria sanidade, por um espaço de saúde que as acolhesse, que lhes confirmasse a condição do humano, do crescimento, da vida. Algumas lutavam, argumentavam e apontavam suas necessidades de forma clara e precisa, enquanto outras demonstravam descrença no outro, tornando-se uma caricatura do que poderia ser uma criança. Desapegadas e com dificuldade de estabelecer vínculos, viviam em estado de tensão e alerta que as impedia de vivenciar outras formas de relação e convívio. Estavam impedidas de manifestar seu si mesmo e de criar e brincar.

A situação dessas crianças chamava a atenção, principalmente por forçar as pesquisadoras a olhá-las. Elas mantinham um padrão de relacionamento com o mundo que as colocava em alerta. A convivência diária com as crianças e adolescentes mostrava que nem tudo era tranquilo: os conflitos eram diários e corriqueiros, assim como os palavrões e as agressões frequentes constituíam a forma utilizada por muitos na resolução

Q

- Os dois brinquedistas eram moradores da comunidade e foram contratados pela Associação de Moradores. As duas estagiárias realizavam estágio no Centro de Convivência. 
de conflitos e diferenças. Observava-se que as diferenças não eram aceitas, o princípio era o da exclusão e não o da complementaridade. Os jogos e as brincadeiras baseavam-se sempre em quem era o melhor e quem era o pior. O individualismo era sempre pautado na luta pela sobrevivência: quem pode mais leva a melhor. Era preciso ficar alerta, usar esperteza, ser mais rápido para conseguir vantagens em detrimento do coletivo. $\mathrm{O}$ outro não era tão importante. Era preciso a todo o momento contê-las, ficar ao lado, impedir que brigassem ou colocar limites para não quebrarem brinquedos ou móveis. Preocupadas em reagir a um ambiente invasivo, esqueciam-se de brincar. A função do ambiente de prover o cuidado e permitir que surgisse o desejo de brincar parecia não estar disponível para muitas dessas crianças.

Os princípios da teoria do amadurecimento faziam cada vez mais sentido na leitura do território e da brinquedoteca. A falta de continuidade dos serviços oferecidos provocava nas crianças a incerteza, a instabilidade e, para muitas, reforçava a descrença no outro. A confiabilidade e a fidedignidade tornavam-se necessárias não apenas para as crianças e adolescentes, mas também para os brinquedistas e estagiários. A provisão ambiental proposta na intervenção deveria dar sustentação e acolhimento a todos: crianças, adolescentes, brinquedistas e estagiários. Assim, começou-se a introduzir uma organização e um olhar específico tanto para cada criança quanto para o grupo inteiro. Se na teoria winnicottiana o brincar é um dos mais importantes sinais de saúde, no ambiente da brinquedoteca o cuidado traduzia-se de diversas maneiras, de acordo com a necessidade de cada criança, desde o acolhimento, o reconhecimento de cada um, o respeito a sua singularidade e subjetividade, até a noção de continuidade de que no dia seguinte todos se veriam novamente.

A partir da organização proposta nessa intervenção, a brinquedoteca passou a funcionar no período da manhã de segunda a quinta-feira, e no período da tarde às terças e quintas-feiras. Os grupos não eram divididos por faixa etária, porém, como frequentavam a brinquedoteca no horário oposto ao da escola, a maioria das crianças que frequentavam a brinquedoteca no período da manhã tinham de 7 a 15 anos, enquanto no período da tarde predominavam crianças menores. O 774 trabalho realizava-se sempre em duplas, para que os brinquedistas pudessem atender às necessidades das crianças com mais atenção. O cuidado com o brincar era uma das facetas do acolhimento. Um olhar mais atento, uma pergunta sobre aquilo de que mais gostavam, o que faziam, do que não gostavam e o por quê eram sinais para novos relacionamentos se estabelecerem. Olhar o outro, provocar nele formas de humanidade, reconhecê-lo como importante e único - isso é o que toda mãe faz, é o que todo ambiente suficientemente bom deve fazer.

A roda de conversa era um recurso utilizado antes ou depois do trabalho de grupo para quem quisesse participar; nesses momentos conseguia-se aglutinar todos, crianças e brinquedistas, podendo conversar sobre o acontecido no dia e sobre planejamentos futuros. Em momentos nos quais o brincar compartilhado apresentava-se muito confuso e o diálogo pouco aparecia, a roda de conversa foi um instrumento importante. Nessa roda, as crianças expunham seus desejos, o que gostariam de fazer, possivelmente um planejamento para o próximo dia ou suas reivindicações. Tentava-se possibilitar, nesses momentos, que as crianças pudessem conversar e refletir sobre o que havia acontecido e planejar o que poderia acontecer no próximo grupo. As regras não eram fixas e, dependendo do dia, conversa-se sobre algo que emergia do grupo, como por exemplo, as brigas, as regras coletivas para o funcionamento da brinquedoteca, a festa junina ou o piquenique. Um pouco de organização foi-se fazendo necessário para esse espaço de brincar.

Para sustentar esse trabalho, foi preciso pensar na organização da equipe, do espaço e dos grupos de crianças. Tornava-se urgente estabelecer encontros com a equipe durante a semana, para refletir acerca do trabalho, das crianças e das atividades em andamento, além de organizar a estruturação do material e do espaço. A primeira e mais premente necessidade era organizar as crianças em grupos e horários definidos, pois não havia como atender a todos diariamente. O espaço ficava tumultuado e os brinquedistas não conseguiam oferecer a atenção necessária a todos. Na história da brinquedoteca havia sempre relatos de crianças pulando o muro para entrar após terem sido barradas na porta. De um lado, para os brinquedistas e estagiários, isso constituía falta de limites, certa provocação e indisciplina; notava-se que talvez faltasse a eles compreensão do 
processo de organização de grupos. De outro, toda vez que se tentava explicar às crianças a divisão de grupos, percebia-se que elas se sentiam lesadas. Em um ambiente que privilegia a lei do mais forte e do que tem mais, em que prepondera a falta, barrar a entrada na brinquedoteca era explicitamente dizer à criança que ela era preterida. Na discussão em equipe percebeu-se que as crianças, para entenderem a proposta, teriam que participar da mesma e compreendê-la totalmente. Assim, nas rodas de conversa colocava-se a dificuldade que aparecia para que todos pudessem brincar quando a brinquedoteca estava superlotada, e perguntava-se o que poderia ser feito para resolver o problema, e como se poderia encontrar uma solução em conjunto.

Por consenso, optou-se por limitar o número de crianças em cada grupo. Todos acreditaram que era importante dividir os grupos, porém, concretamente, o problema persistia. Pensou-se então em um instrumento gráfico, concreto, no qual as crianças pudessem visualizar como ocorreriam as mudanças e marcar seu compromisso com as mudanças que estavam ocorrendo. Juntamente com as pesquisadoras, as crianças construíram um grande cartaz com marcação dos dias e horários que podiam frequentar e, após, cada uma escolheu dois dias da semana. Cada grupo poderia receber até 25 participantes, e, se o número-limite não estivesse preenchido, poderiam participar crianças não inscritas naquele horário.

As crianças e adolescentes estipularam o horário em período contraposto ao da escola. Esse acordo coletivo produziu um movimento interessante entre as crianças e adolescentes. Um deles se referiu à possibilidade de escolha e comprometimento. Ao optar por um determinado horário e dia, a criança começava a fazer parte de um grupo por opção própria. Na hora da escolha, as crianças perguntavam quem fazia parte do grupo e sempre estavam atentas aos primos e amigos que dele participavam. Começaram a combinar entre si e a permutar os dias, conversando sobre a possibilidade de virem juntos. Surgiu a possibilidade de negociação, pois algumas vezes as crianças colocavam horários não compatíveis com seus compromissos escolares e familiares, e precisavam encontrar outro horário ou dia - daí a necessidade de conversar, trocar com alguém, negociar e compreender as dificuldades do outro e a sua própria. A certeza de que o grupo formado estaria lá trouxe contornos para esse grupo e ele passou a criar regras coletivas e a organizar-se como tal. A possibilidade de ter grupos mais ou menos fixos com a organização dos dias e horários auxiliou a construir certa grupalidade e a introduzir projetos coletivos.

Conseguiu-se construir coletivamente essas regras, mas muitas outras estavam por vir. A falta de cuidado consigo, com o outro e com o ambiente físico gerava situações emergenciais que foram sendo tratadas ao longo do ano. Nem todos faziam a arrumação dos brinquedos e materiais após cada grupo, sendo essa mais uma das preocupações que derivavam do cuidado com o ambiente. Percebia-se que as crianças se ressentiam de ajudar na arrumação, como se estivessem se submetendo a uma exploração de seu trabalho. Algumas diziam aos brinquedistas que eles não poderiam obrigá-las a arrumar o lugar, que não eram empregadas de ninguém.

A equipe de pesquisadores compreendeu que era necessário introduzir novas formas de organização com novos elementos e sem nenhuma exclusão, pois a questão ia além do conceito moral de limpo/sujo, certo/errado. Na rotina de trabalho passou-se a avisar com 20 ou 15 minutos de antecedência que o grupo estava terminando e que eles poderiam começar a se preparar para concluir as brincadeiras e começar a guardar os materiais e brinquedos utilizados. Essa providência foi fundamental, pois estabeleceu uma preparação anterior ao término da brincadeira. Antes, as crianças resistiam à arrumação e saíam irritadas porque queriam continuar brincando; além de não guardarem os jogos ou brinquedos, acabam por torná-los alvo de sua raiva e os quebravam ou danificavam.

Com essa preparação, abriu-se a possibilidade de negociarem com os brinquedistas cinco minutos a mais, explicarem que não daria para terminar o jogo e indagarem sobre o que fariam. Com calma e mais tempo disponível, os brinquedistas começavam, com a ajuda das crianças, a organizar a brinquedoteca para outro grupo, possibilitando ainda que elas se despedissem do espaço. As crianças começaram a perceber que os brinquedistas se preocupavam com os materiais, a limpeza e a integridade do espaço. Eram apontada a importância de se limpar a sala depois das brincadeiras e organizar o espaço. 
Outras ações contribuíram para que a organização do trabalho obtivesse êxito. As experiências vividas na brinquedoteca provocaram um deslocamento dos comportamentos reativos e mostraram que as falhas ambientais poderiam, em grande parte, ser reparadas por meio de um ambiente provedor de cuidados e, assim, oferecer uma continuidade do processo de amadurecimento. Ao longo de 2007 foi possível observar as mudanças ocorridas no espaço e nas crianças que o frequentavam. De usuários da brinquedoteca passaram a atores do trabalho. Alguns adolescentes começaram a atuar como monitores dos grupos de crianças. Além disso, passaram a reivindicar um espaço próprio, onde pudessem ouvir música, conversar e conviver. Os momentos de brincadeira tornaram-se prazerosos: meninos e meninas traziam para a brinquedoteca os brinquedos de que mais gostavam e que queriam compartilhar. As negociações tornaram-se mais frequentes, e os conflitos foram, ao longo do ano, sendo resolvidos de outro modo que não o embate corporal. O brincar compartilhado trouxe a possibilidade de experimentar o que o outro sugeria ou de modificar sua brincadeira com a brincadeira do outro. As interferências do coletivo propiciaram novas formas de integração e criaram novas possibilidades de expressão.

\section{Considerações Finais}

Ao retomar o tema do brincar e as infinitas possibilidades de estudo que dele emergem, esta pesquisa constatou que o brincar aparece como uma possibilidade que a criança tem de vivenciar processos de saúde, de viver criativamente, de retomar processos de amadurecimento interrompidos. Na prática cotidiana, o brincar propiciou às crianças estarem em contato com o mundo e com a cultura, e de se apropriarem desses elementos, revelando uma maneira de ser, de estar no mundo e de expressar-se. $\mathrm{O}$ ambiente proposto na brinquedoteca potencializou a importância do espaço compartilhado como mediador entre as necessidades e desejos das crianças e os limites e possibilidades da realidade externa. Nessa intervenção, o papel do adulto foi acolher as diferenças, estar junto quando o brincar não era possível e fornecer segurança suficiente para que o brincar criativo pudesse fazer parte da vida dessas

776 crianças.
O ambiente foi sendo descoberto de forma criativa, destruído, criado, reinventado, oferecendo a oportunidade de uma ilusão criativa, agente de descobrimento, mesmo sabendo-se que o mundo já estava lá para ser criado. As crianças puderam entrar em contato com um ambiente que as acolheu sem invasões ou encontros inesperados e incompreensíveis, e que estabeleceu limites e contornos sem que elas perdessem a dignidade. Como uma mãe suficientemente boa, a brinquedoteca suficientemente boa tem que ser capaz de adaptarse ativamente às necessidades de cada criança que a frequenta, além de manter um compromisso fundamental com todos: ali é o lugar onde se brinca, lugar que tem o compromisso de oferecer condições para que a brincadeira seja possível.

A partir dessa intervenção, conclui-se que o profissional de saúde precisa compreender melhor o modo como a violência atinge as crianças e como se pode combatê-la oferecendo-Ihes outras formas de existência. À sociedade cabe compreender que as mais variadas formas de exclusão e desigualdade social estão impedindo o processo de amadurecimento pessoal e multiplicando fatores de risco que deterioram gravemente a vida dessas crianças. $O$ trabalho de um profissional de saúde deve voltar-se para transformar realidades, traçando novos caminhos na criação de políticas públicas mais justas na atenção à infância e à adolescência. Nesse sentido, o trabalho desenvolvido por meio de brinquedotecas que apostam na construção de comunidades pode contribuir para a constituição de políticas públicas mais inclusivas.

\section{Referências}

Araujo, C. S. (2007). Uma abordagem teórica e clínica do ambiente a partir de Winnicott. Tese de doutorado não-publicada, Pontifícia Universidade Católica de São Paulo.

Cunha, N. H. S. (2007). Brinquedoteca:um mergulho no brincar. São Paulo: Boitempo.

Fortuna, T. R. (2008). Para um modelo de brinquedotecas para a América Latina. Recuperado em maio 15, 2009, disponível em <www.brinquedoteca.com.br>.

Galletti, M. C. (2007). Itinerários de um serviço de saúde mental na cidade de São Paulo: trajetórias de uma saúde poética. Tese de doutorado não-publicada, Pontifícia Universidade Católica de São Paulo. 
Lacôrte, M. T. (2008). O meio ambiente e sua importância no tratamento da tendência antissocial. In J. T. Rosa \& I. F. Motta (Orgs.), Violência e sofrimento de crianças e adolescentes na perspectiva winnicottiana. São Paulo: Fapesp.

Thiollent, M. (2003). Metodologia da pesquisa-ação. São Paulo: Cortez.

Winnicott, D. W. (1975). A criatividade e suas origens. In D. W. Winnicott. Obrincar e a realidade. Rio de Janeiro: Imago. (Originalmente publicado em 1959).

Winnicott, D. W. (1983a). Da dependência à independência no desenvolvimento do indivíduo. In D. W. Winnicott. O ambiente e os processos de maturação: estudos sobre a teoria do desenvolvimento emocional. Porto Alegre: Artes Médicas. (Originalmente publicado em 1963).

Winnicott, D. W. (1983b). Os doentes mentais na prática clínica. In D. W. Winnicott. O ambiente e os processos de maturação: estudos sobre a teoria do desenvolvimento emocional. Porto Alegre: Artes Médicas. (Originalmente publicado em 1963).

Winnicott, D. W. (1983c). Distorções do ego em termos de falso e verdadeiro self. In D. W. Winnicott. O ambiente e os processos de maturação: estudos sobre a teoria do desenvolvimento emocional. Porto Alegre: Artes Médicas. (Originalmente publicado em 1960).

Winnicott, D. W. (1990). Natureza humana. Rio de Janeiro: Imago.

Winnicott, D. W. (1999a). A delinquência como sinal de esperança. In D. W. Winnicott. Tudo começa em casa. São Paulo: Martins Fontes. (Originalmente publicado em 1967).

Winnicott, D. W. (1999b). Tipos de psicoterapia. In D. W. Winnicott. Tudo começa em casa. São Paulo: Martins Fontes. (Originalmente publicado em 1961).

Winnicott, D. W. (2000). A tendência antissocial. In D. W. Winnicott. Da pediatria à psicanálise: obras escolhidas. Rio de Janeiro: Imago. (Originalmente publicado em 1956).

Recebido em: 11/11/2010

Versão final em: 14/5/2012

Aprovado em: 5/6/2012 
